\title{
Crowns in pediatric dentistry $-\mathrm{A}$ Review on the failures
}

\author{
Anupama S Prakash and Vignesh Guptha Raju* \\ Department of Pedodontics and Preventive Dentistry, Karpaga vinayaga institute of dental sciences, Tamil Nadu, India
}

\begin{abstract}
Several crowns are used as full coronal restoration in primary teeth. The literature was reviewed in order to investigate the failure and the reasons for failure of pediatric crowns. Electronic databases were screened, and eligible studies were hand-searched to find clinical studies evaluating the survival of different crowns placed in primary teeth with follow-up. Among those, an elevated number of failures were reported with every other type of crown. The high variation on failure rate among the crowns can be due to several contributing factors out of which children's behaviour during the clinical procedure can be the most vital. All the factors leading to the failure of each type of crown are thoroughly reviewed and discussed.
\end{abstract}

\section{Introduction}

Treatment of caries in the primary dentition is still an integral part of child healthcare. In pediatric dentistry several options are available for providing full coverage restoration for the primary dentition, with each approach having advantages and disadvantages. Commonly used full coverage crowns include stainless steel crowns and its modifications, polycarbonate crowns and strip crowns [1]. Though these materials have shown satisfactory properties and results, failures are still being reported. In the past, stainless steel crowns (SSCs) have been shown to provide the most durable restorative material for primary molars. However, they have been mainly recommended where pulp therapy has been performed, or in teeth with multi-surface restorations due to developmental defects or caries, or where other restorative materials are likely to fail [2]. The issue of durability of stainless-steel crowns compared to multi surface amalgam restorations continues to be unresolved in the paediatric dental literature, and clinicians frequently select the restoration based upon personal experience. The SSC is extremely durable, relatively inexpensive, subject to minimal technique sensitivity during placement, and offers the advantage of full coronal coverage. Despite the favorable qualities mentioned, SSCs have a major drawback-namely, their poor esthetic appearance [1]. Important parameters such as patients' cooperation during treatment, caries activity, different material performances within one group of restorative materials and operator's experience affect clinical longevity of restorations in primary teeth. The success of SSC depends on the quality of the tooth preparation, selection and adjustment of an appropriate crown, and the luting cement [3-6].

Open-face SSCs are another cosmetic solution to stainless steel crowns, although they also have several disadvantages [7]. The procedure is time consuming and requires additional preparation and use of multiple materials. Excellent esthetic appearance with acceptable longevity has been obtained from resin-based crowns (strip crowns) for decayed and/or fractured anterior primary incisors but they are technique-sensitive restorations. Polycarbonate crowns are another treatment approach to address the restoration and esthetics of anterior primary decayed teeth [7]. They are more esthetic than stainless steel crowns, easy to trim and adjust and requires less chair side time. Each of these methods has short comings but each of them can be used at some time. The search for the ideal full coverage restorations in pediatric dentistry continues. Operator preferences, esthetic demands by parents, the child's behavior, and moisture and hemorrhage control are all variables which affect the decision and ultimate outcome of whatever restorative outcome is chosen.

\section{Criteria for stainless steel crown failure}

Any restoration identified by the dentist which needs to be replaced due to structural breakdown is considered as a failure. Roberts, et al. assessed SSC failure, expanding the criteria of Allan in 1969, crowns classified as "true" failures showed: evidence in the record of replacement (or need for replacement); any other form of retreatment (including pulpotomy); or tooth extraction (or need for extraction) due to pulpal or radicular pathology [2,8]. Time interval between placement of crown and last treatment series the crown was recorded as successful, is called as period of success of a crown. In this study, since crowns were not examined clinically, a computer-appropriate definition was used to assign the time to failure of a crown. This was defined as the number of months between placement of the crown and the last treatment series in which the crown was recorded as successful, plus one-half of the time interval in months from the last record of success to the first treatment series in which the crown was recorded as a failure. This definition assumed that failure occurred at the midpoint between treatment series.

The study showed that crowns placed in children aged under four years are predicted to have a higher failure rate than those placed in children 4 years and older. Crowns placed over formocresol pulpotomies show a greater relative risk (3.97 times) of failure than those placed over vital coronal pulps. Inadequately contoured crown and residues of set cement remaining in contact with the gingival sulcus are suggested as reasons for gingivitis associated with preformed metal crowns, and a preventive regime including oral hygiene instruction are recommended be incorporated into the treatment plan [9].

${ }^{\star}$ Correspondence to: Vignesh Guptha Raju, Department of Pedodontics and Preventive Dentistry, Karpaga vinayaga institute of dental sciences, Tamil Nadu, India, E-mail: vigneshguptha88@gmail.com

Received: March 10, 2020; Accepted: March 20, 2020; Published: March 27, 2020 
The main reasons for preformed metal crown failure reportedly are crown loss and perforation [2,9-11]. SSC failures are more likely to be observed among patients with developmental disabilities, but not necessarily among patients with significant medical histories. The major reason for stainless steel crown failures was reported to be occlusal wear leading to perforation of the surface [12]. If crown perforation from occlusal wear is a significant factor leading to crown failures in pediatric patients, it should not be surprising that higher crown failure rates would be found in patients who are diagnosed with developmental disabilities. Hence, children with cerebral palsy and those with musculoskeletal problems or severe mental retardation who have been reported to have higher levels of bruxism and malocclusion show significant failure rates of SSCs $[13,14]$. Conservative amalgam or composite restorations may thus be the appropriate treatment of choice in such patients [15].

\section{Failures occuring in each stage during placement of ssc}

Tooth preparation: Duggal and Curzon recommended trying the selected crown for size before carrying out any lingual or buccal reduction. Any ledge or step present at the mesial or distal finishing line will create difficulty in seating the crown and the clinician may then trim the crown unnecessarily when it is the ledge or step that should be removed [16-19].

Selection of crown size: The selected crown should restore the contact areas and occlusal alignment of the prepared tooth. Improper selection of crown size and omission of a bite-wing radiograph at the crown try-in stage leads to margin overextension in the interproximal area [9]. However, exposure of the patient to ionizing radiation for assessment of a preformed metal crown (PMC) margin may be considered inappropriate [9].

Crown adaptation in special cases. When multiple crowns are to be placed in the same quadrant, the adjacent proximal surfaces of the teeth should be reduced more than usual to facilitate placement of the crowns $[20,21]$. When there is no adjacent tooth, proximal tooth reduction should still be carried out to avoid an excessive crown margin overhang [22]. This is especially important on the distal surface of the second primary molar prior to eruption of the first permanent molarany overhang here could displace the eruption path of the permanent molar [22-24]. When there is mesiodistal drift of the teeth, resulting in loss of arch length and when there is reduced mesiodistal dimension of the tooth crown to be prepared, it is required that the PMC have its mesial and distal surfaces flattened a slight amount with pliers or the contact area disced to thin it $[17,20,22,25]$.

Risks: periodontal concern. Incidence of gingivitis was higher in posterior teeth restored with nickel chromium crowns and it was found to be more strongly associated with poor fitting crowns [26]. Gingivitis can occur if the crown margins are inadequately contoured or if residues of set cement remain in contact with the gingival sulcus [19,26-29].

Nickel allergy: Nickel hypersensitivity is more prevalent in females than males and is considered to be associated with pierced ears or metal buttons in clothing [9]. Adjustment of a crown by cutting or crimping the margin will leave a roughened surface and if these areas are not smoothed and polished to a high gloss then the likelihood of corrosion increases [30-32].

Esthetics: Improved standards of living and better education over the last 20 to 30 years have given rise to higher expectations of treatment $[33,34]$. Some parents have expressed dislike of the appearance of a
PMC with crowns for the lower first primary molars causing the most comment $[35,36]$. A well-known method of improving the appearance of metal crowns by cutting a window in the buccal wall of the cemented crown and restoring this with composite resin is compromised by gingival bleeding when the composite is placed and is a time-consuming procedure [37,38].

\section{Criteria for failure of resin faced stainless steel crowns}

In the above-mentioned study by Roberts, Lee and Wright, about $1 / 4^{\text {th }}$ of the resin facings were completely lost in 3 years or less. Increased overbite was significantly associated with an increased facing failure rate indicating tooth position influences treatment outcome [39] (Table 1).

\section{Failures of esthetic stainless steel crowns}

SSCs have one potential drawback, despite their greater than $95 \%$ success rate: the unattractive colour of the restorative material. This marked the rise of the esthetic stainless steel crowns. Esthetic SSCs have several shortcomings relative to SSC restorations. They require a greater reduction of tooth structure during preparation than in the case for traditional SSCs [40]. In addition, esthetic SSCs cannot always be crimped to fit to the prepared tooth, and repair of fractured coatings may entail complete replacement $[41,42]$. There is also a greater need for occlusal reduction with esthetic SSCs, which can increase the risk of exposing vital pulp. Although the prognosis for vital pulpotomy is good the procedure increases chair time and cost $[43,44]$. The shape of an esthetic SSC cannot be altered, because this would change the rigid metal coping structure beneath the somewhat brittle composite, leading to the possibility of future fracture [39]. Fracture of an esthetic SSC can lead to loss of space in the developing pediatric dentition, as well as increased retention of plaque [42]. In this situation, the tooth may remain free of caries, but the esthetic purpose for using this type of restoration will not have been achieved.

In a study by Roberts, et al. [39] esthetic SSCs showed adverse esthetic outcomes, such as chipping, discoloration or loss of coating,

Table 1. Clinical evaluation criteria

\begin{tabular}{|c|c|}
\hline Treated tooth exfoliated & $\begin{array}{l}0=\text { yes } \\
1=\text { no }\end{array}$ \\
\hline Crown / Facing retention & $\begin{array}{l}0=\text { Crown intact } \\
1=\text { Partial or complete facing loss } \\
2=\text { Loss of crown }\end{array}$ \\
\hline Facing fracture & $\begin{array}{l}0=\text { No fracture } \\
1=\text { Small fracture (less than } 1 / 4 \text { facing) } \\
2=\text { Bulk fracture (greater than } 1 / 4 \text { facing) }\end{array}$ \\
\hline Area of facing loss & $\begin{array}{l}0=\text { No loss } \\
1=\text { Incisal } 1 / 3 \text { only } \\
2=\text { Incisal } 1 / 2 \\
3=\text { Entire facing }\end{array}$ \\
\hline Interface failure site & $\begin{array}{l}0=\text { No failure } \\
1=\text { Resin }- \text { Resin } \\
2=\text { Resin }- \text { Metal } \\
3=\text { Metal }- \text { Metal }\end{array}$ \\
\hline Facing repair & $\begin{array}{l}0=\text { None } \\
1=\text { Repair present }\end{array}$ \\
\hline Facing color & $\begin{array}{l}0=\text { Unchanged } \\
1=\text { Minor deviation from original } \\
2=\text { Unacceptable discoloration }\end{array}$ \\
\hline Facing wear & $\begin{array}{l}0=\text { No wear } \\
1=\text { Incisal wear only } \\
2=\text { Greater than incisal wear }\end{array}$ \\
\hline Facing surface texture & $\begin{array}{l}0=\text { Smooth } \\
1=\text { Minor roughness } \\
2=\text { Unacceptable surface roughness }\end{array}$ \\
\hline
\end{tabular}


after 2 years. Therefore, although esthetic SSCs may represent an esthetic improvement over traditional SSCs, the increased potential for pulpal exposure, the difficulty of achieving a clinically acceptable fit and the tendency of the esthetic coating to fracture are potential shortcomings.

\section{Failures of pre-veneered crowns}

Aboushelib's, et al. [45] study of preveneered crowns concluded that the challenges of using the preveneered crowns include the fact that they are relatively inflexible yet brittle which means that when the resin is overloaded with excessive compression or other forces, they tend to break. Hence, they begin to develop fractures with time because of their brittle nature. Preveneered crowns are also unable to withstand a lot of force and pressure because of crimping especially the lingual surface due to the fact that the crowns are forced on the teeth. In getting the preveneered crowns fixed, the teeth often have to be subjected to significant removal of tooth structure in an effort to ensure that the crown is a passive fit and this affects the strength of the crown and teeth to withstand the external force $[46,47]$. Another reservation in using preveneered crown is due to the limited shades available and the difficulty in inserting multiple approximating crowns in patients who have problems of crowding or loss of space due to bulk [48]. Long-term retention and resistance to fracture of the veneer has been shown to be somewhat low [49].

\section{Composite strip crowns}

These are bonded crowns, when it comes to bonded crowns the 3 factors that play a major role in clinical success are: amount of tooth structure required for bonding, moisture control and haemorrhage control. This is a highly technique sensitive restoration which makes moisture control inadequate if the child is uncooperative, restless and stressed during the treatment. Eidelman, et al. [50] reported better results for strip crowns placed under general anaesthesia than for those done under sedation. High failure rate of $51 \%$ over a period of 2 years was seen in a study by Tate, et al. [51] where strip crowns were placed under general anaesthesia and endodontically treated teeth were included as well. Endodontic treatment can also affect the overall retention of these crowns as these teeth are usually more destructed [52].

\section{Zirconia crowns}

Improperly polished and only glazed zirconia can be destructive to the opposing tooth structure [53]. The abrasive effect of zirconia crowns negatively impacts the tooth root and other neighbouring teeth [54].

\section{Conclusion}

1. From the above literature it is evident that every crown used to treat children has it's own merits and demerits. Survival time variation may also be closely related to the differences in treatment decision by the dentist, who can adopt a proactive or a reactive position in relation to dental intervention and this becomes critical especially while attending children.

2. Factors for longevity of crowns depends on dental material properties, operator ability and age and cooperation of the child to accept the treatment.

3. To summarise, composite strip crowns have lower success rate and higher gingival inflammation. Pre-veneered SSCs are retentive, but can have facial veneer fracture. Pre-fabricated zirconia crowns are retentive and gingival friendly but expensive.

\section{Conflict of interest}

None

\section{References}

1. Garg V, Panda A, Shah J, Panchal P (2016) Crowns in pediatric dentistry: A review. Journal of Advanced Medical and Dental Sciences Research 4: 41.

2. Roberts JF, Attari N, Sherriff M (2005) The survival of resin modified glass ionomer and stainless steel crown restorations in primary molars, placed in a specialist paediatric dental practice. Br Dent $J$ 198: 427-431. [Crossref]

3. Mathewson RJ, Lu KH, Talbei R (1974) Dental cement retentive force comparison on stainless steel crowns. J Calif Dent Assoc 2: 42-45. [Crossref]

4. Noffsinger DP, Jedrychowski JR, Caputo AA (1983) Effect of polycarboxylate and glass ionomer cements on stainless steel crown retention. Pediatr Dent 5: 68-71. [Crossref]

5. Spedding RH (1984) Two principles for improving the adaptation of stainless steel crowns to primary molars. Dent Clin North Am 28: 157-175. [Crossref]

6. Rector JA, Mitchell RJ, Spedding RH (1985) The influence of tooth preparation and crown manipulation on the mechanical retention of stainless steel crowns. ASDCJ Dent Child 52: 422-427. [Crossref]

7. Waggoner WF, Kupietzky A (2001) Anterior esthetic fixed appliances for the preschooler: considerations and a technique for placement. Pediatr Dent 23: 147-150. [Crossref]

8. Allan DN (1969) The durability of conservative restorations. Br Dent $J$ 126: 172-177. [Crossref]

9. Randall RC (2002) Preformed metal crowns for primary and permanent molar teeth review of the literature. Pediatr Dent 24: 489-500. [Crossref]

10. Hickel R, Kaaden C, Paschos E, Buerkle V, García-Godoy F, et al. (2005) Longevity of occlusally stressed restorations in posterior primary teeth. Am J Dent 18: 198-211. [Crossref]

11. Dhar V, Hsu KL, Coll JA, Ginsberg E, Ball BM, et al. Evidence-based Update of Pediatric Dental Restorative Procedures: Dental Materials. J Clin Ped Dent 39: $303-$ 310. [Crossref]

12. Roberts JF, Sherriff M (1990) The fate and survival of amalgam and preformed crown molar restorations placed in a specialist paeditric dental practice. Br Dent 169: 237-244.

13. Pope JE, Curzon ME (1991) The dental status of cerebral palsied children. Pediat Dent 13: 156-162. [Crossref]

14. Christensen JR, Fields HW (1994) Oral habits. Pediatric Dentistry: Infancy Through Adolescence, 2nd ed. JR Pinkham, et al eds. Philadelphia: WB Saunders Company.

15. Ng MW, Tate AR, Needleman HL, Acs G (2001) The influence of medical history on restorative procedure failure rates following dental rehabilitation. Pediatric dentistry 23: 487-490. [Crossref]

16. Full CA, Walker JD, Pinkham JR (1974) Stainless steel crowns for deciduous molars. $J$ Am Dent Assoc 89: 360-364. [Crossref]

17. Duggal MS, Curzon MEJ, Fayle SA, Pollard MA, Robertson AJ (1995) Restorative Techniques in Paediatric Dentistry. (1st Edn). Martin Dunitz, London.

18. Mink JR, Bennett IC (1968) The stainless steel crown. J Ont Dent Assoc 45: 420-430. [Crossref]

19. More FG, Pink TC (1973) The stainless steel crown: a clinical guide. J Mich State Dent Assoc 55: 237-242. [Crossref]

20. Nash DA (1981) The nickel-chromium crown for restoring posterior primary teeth. $J$ Am Dent Assoc 102: 44-49. [Crossref]

21. McEvoy SA(1977) Approximating stainless steel crowns in space-loss quadrants. $A S D C$ $J$ Dent Child 44: 105-107. [Crossref]

22. Fayle SA (1999) UK national guidelines in paediatric dentistry. Int J Paediatr Dent 9: $311-314$

23. Croll TP (1999) Preformed posterior stainless steel crowns: An update. Compendium 20: 89-92. [Crossref]

24. Croll TP, McKay MS, Castaldi CR (1981) Impaction of permanent posterior teeth by over extended stainless steel crown margins. J Pedodont 5: 240-244. [Crossref]

25. Ligh RQ (1987) Special considerations for atypical stainless steel crown situations Hawaii Dent J 18: 10-23. 
26. Goto G, Imanishi T, Machida Y (1970) Clinical evaluation of preformed crown for deciduous teeth. Bull Tokyo Dent Coll 11: 169-176. [Crossref]

27. Henderson HZ (1973) Evaluation of the preformed stainless steel crown. ASDC J Dent Child 40: 353-358. [Crossref]

28. Brook AH, King NM (1982) The role of stainless crowns. Part 1. Properties and techniques. Dent Update 9: 25-26, 28-30. [Crossref]

29. Myers DR (1975) A clinical study of the response of the gingival tissue surrounding stainless steel crowns. ASDC J Dent Child 42: 281-284. [Crossref]

30. Grimsdottir MR, Gjerdet NR, Hensten-Petersen A (1992) Composition and in vitro corrosion of orthodontic appliances. Am J Orthod Dentofacial Orthop 101: 525-532. [Crossref]

31. Bishara SE, Barrett RD, Selim MI (1993) Biodegradation of orthodontic appliances. Part II. Changes in the blood level of nickel. Am J Orthod Dentofacial Orthop 103: 115-119. [Crossref]

32. von Fraunhofer JA (1997) Corrosion of orthodontic devices. Semin Orthod 3: 198-205. [Crossref]

33. Eaton KA (1998) Awareness of periodontal diseases: the professional and the civil servant. Int Dent J 48: 248-255. [Crossref]

34. Humphris GM, Cooper CL (1998) New stressors for GDPs in the past ten years: a qualitative study. $\mathrm{Br}$ Dent $J$ 185: 404-406. [Crossref]

35. Croll TP, Riesenberger RE [1986] Primary molar stainless steel crown restoration. Quintessence Int 17: 221-226. [Crossref]

36. Roberts JF (1983) The open-faced stainless steel crown for primary molars. ASDC J Dent Child 50: 262-263. [Cossref]

37. Waggoner WF, Cohen H (1995) Failure strength of four veneered primary stainless steel crowns. Pediatr Dent 17: 36-40. [Crossref]

38. Croll TP, Helpin ML (1996) Preformed resin-veneered stainless steel crowns for restoration of primary incisors. Quintessence Int 27: 309-313. [Crossref]

39. Roberts C, Lee JY, Wright JT (2001) Clinical evaluation of and parental satisfaction with resin-faced stainless steel crowns. Pediatric Dentistry 23: 28-31. [Crossref]

40. Fuks AB, Ram D, Eidelman E (1999) Clinical performance of esthetic posterior crowns in primary molars: a pilot study. Pediatr Dent 21: 445-448. [Crossref]
41. Waggoner WF, Cohen H (1995) Failure strength of four veneered primary stainless steel crowns. Pediatr Dent 17: 36-40. [Crossref]

42. Ram D, Fuks AB, Eidelman E (2003) Long-term clinical performance of esthetic primary molar crowns. Pediatr Dent 25: 582-584. [Crossref]

43. Dean JA, Mack RB, Fulkerson BT, Sanders BJ (2002) Comparison of electrosurgical and formocresol pulpotomy procedures in children. Int J Paediatr Dent 12: 177-182. [Crossref]

44. Beattie S, Taskonak B, Jones J, Chin J, Sanders B, et al. (2011) Fracture resistance of 3 types of primary esthetic stainless steel crowns. J Can Dent Assoc 77: b90. [Crossref]

45. Aboushelib MN, Kleverlaan CJ, Feilzer AJ (2006) Microtensile bond strength of different components of core veneered all-ceramic restorations: Part II: Zirconia veneering ceramics. Dental materials 22: 857-863. [Crossref]

46. Croll TP (1998) Primary incisor restoration using resin-veneered stainless steel crowns ASDC J Dent Child 65: 89-95. [Crossref]

47. MacLean J, Champagne C, Waggoner W, Ditmyer M, Casamassimo P (2007) Clinical outcomes for primary anterior teeth treated with preveneered stainless steel crowns. Pediatr Dent 29: 377-382.

48. Baker LH, Moon P, Mourino AP (1996) Retention of esthetic veneers on primary stainless steel crowns. J Dent Child 63:185-189. [Crossref]

49. Gupta M, Chen JW, Ontiveros JC (2008) Veneer Retention of Preveneered Primary Stainless Steel Crowns after Crimping. J Dent Child 75: 44-47. [Crossref]

50. Eidelman E, Faibis S, Peretz B (1997) A comparison of restorations for children with early childhood caries treated under general anesthesia or conscious sedation. Pediatr Dent 22: 33-37.

51. Tate AR, Ng MW, Needleman HL, Acs G (2002) Failure rates of restorative procedures following dental rehabilitation under general anesthesia. Pediatr Dent 24: 69-71. [Crossref]

52. Kupietzky A, Waggoner WF, Galea J (2005) Long-term photographical and radiographic assessment of bonded resin composite strip crowns for primary incisors: results after 3 years. Pediatr Dent 27: 221-225. [Crossref]

53. Donovan TE (2008) Factors essential for successful all-ceramic restorations. $J$ Amer Dental Assoc 139: 14S-18S. [Crossref]

54. Tote JV, Godhane A, Das G, Soni S, Jaiswal K, et al. (2015) Posterior Esthetic Crowns in Pediatric Dentistry. Int J Dent Med Res 1: 197-201.

Copyright: (C2020 Prakash AS. This is an open-access article distributed under the terms of the Creative Commons Attribution License, which permits unrestricted use, distribution, and reproduction in any medium, provided the original author and source are credited. 